\title{
MICHEL RIAUDEL SOBRE Ana Cristina Cesar
}

http://dx.doi.org/10.11606/issn.2237-1184.v0i32p172-184

Raquel Machado Galvão ${ }^{I}$

\section{RESUMO}

Entrevista realizada com o professor, tradutor e pesquisador francês Michel Riaudel em junho de 2019. O diálogo parte de questões e de teorias apresentadas na sua tese sobre Ana Cristina Cesar, a fim de revisar as dimensões da obra e das pesquisas a respeito da produção da escritora na atualidade. As perspectivas de leituras apresentadas por Riaudel na conversa abrangem as influências literárias, o aspecto do engajamento literário, as reflexões relacionadas à escrita feminina e a relação entre tradução e criação no percurso intelectual da poeta.

\section{RESUMÉ}

Entretien avec le professeur, traducteur et chercheur français Michel Riaudel, tenu en juin 2019. Le dialogue part de questions et de théories présentées dans sa thèse sur Ana Cristina Cesar, afin de revoir les dimensions dans l'œuvre et de la recherche concernant la production de l'écrivain aujourd'hui. Les perspectives de lectures présentées par Riaudel dans la conversation incluent les influences littéraires, l'aspect de l'engagement littéraire, les réflexions liées à l'écriture féminine et la relation entre traduction et création dans le parcours intellectuel du poète.

\section{PALAVRAS-CHAVE:}

Ana Cristina Cesar; Michel Riaudel; poesia; tradução.

\section{MOTS-CLÉS:}

Ana Cristina Cesar;

Michel Riaudel;

poésie;

traduction.

I Universidade Estadual de Campinas, Campinas, São Paulo, Brasil. 


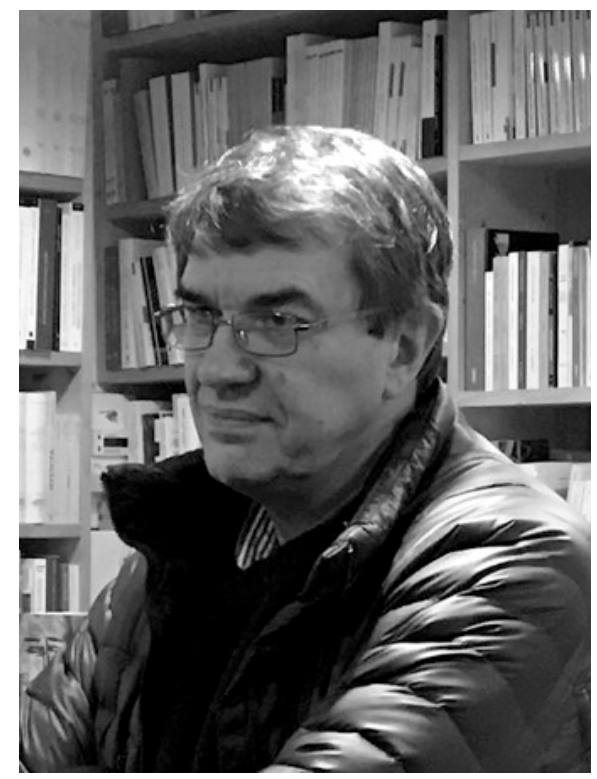

$\mathrm{M}$ francês da área das Letras, vinculado desde 2017 à Sorbonne Université (Paris), tem a trajetória acadêmica e profissional marcadas pela dedicação ao estudo da literatura brasileira. Membro titular do Centro de Pesquisas Interdisciplinares sobre os Mundos Ibéricos Contemporâneos (CRIMIC), desenvolve pesquisas, exposições públicas e aulas na sede da UFR de Estudos Ibéricos e Latino Americanos voltadas, principalmente, para os diálogos históricos entre o Brasil e a França através da literatura, os trânsitos e as traduções da literatura brasileira no estrangeiro, e obras de escritores brasileiros como Graciliano Ramos (1892 - 1953), João Guimarães Rosa (1908 - 1967), Clarice Lispector (1920 - 1977) e Ana Cristina Cesar (1952 - 1983).

O propósito desta entrevista é entreter um diálogo sobre Ana Cristina Cesar e as questões de leituras e teorias presentes no abrangente e profundo trabalho de Riaudel no campo da literatura brasileira contemporânea. Ao longo de 622 páginas, o trabalho de tese Intertextualidade e transferências (Brasil, Estados Unidos e Europa): reescritas da modernidade poética na obra de Ana Cristina Cesar (RIAUDEL, Université Paris X - 2007) reflete sobre a obra da escritora brasileira considerando, para isso, o tripé gênese literária, diálogos literários e tradução-criação.

Responsável pela tradução de Luvas de Pelica e outros poemas de Cesar para o francês (Gants de Peau E autres poèmes, 2005), Michel Riaudel foi um dos primeiros pesquisadores a ter acesso ao acervo pessoal de Ana 
Cristina Cesar, quando este, desde 2005 sob a guarda completa do Instituto Moreira Salles no Rio de Janeiro, ainda estava no apartamento da família da escritora, localizado na rua Toneleros em Copacabana. O primeiro artigo do pesquisador sobre Ana Cristina Cesar, "De Bliss a Luvas de Pelica": a metamorfose de um conto ${ }^{1}$ foi publicado no ano de 1998.

$\mathrm{Na}$ cronologia da historiografia literária, o pesquisador francês localiza as pesquisas acadêmicas sobre Ana Cristina Cesar em três gerações, cujo ponto de partida foi o texto de Silviano Santiago, Singular e Anônimo (1984), seguida pela tese Atrás dos olhos pardos: uma leitura da poesia de Ana Cristina Cesar, defendida na Universidade de São Paulo, em 1990, pela pesquisadora Maria Lucia de Barros Camargo. Entre outros assuntos abordados, é destacada a colaboração de Ana Cristina Cesar para publicações na imprensa brasileira, durante as décadas de 1970 e 1980, somado ao seu trabalho como poeta, tradutora e pesquisadora-intelectual.

I - Por que existe um interesse contínuo na obra desta escritora cuja morte é tida como precoce, mas nem por isso a produção insuficiente para inscrevê-la com a devida importância no campo literário brasileiro? Como você localiza e se localiza nas gerações de críticos-pesquisadores de Ana Cristina Cesar?

M. $R$.: Em relação às três gerações de pesquisadores de Ana Cristina Cesar, a acessibilidade profunda à produção da escritora se dá quando Maria Lúcia de Barros Camargo pesquisa na Universidade de São Paulo, inscrevendo-se na primeira geração, sem respeito à idade, mas ao momento e conteúdos que ela trabalha. Até então, entre as obras da escritora, só existe o A teus pés (1982) e o Inéditos e dispersos (1985), que foi publicado logo na sequência da morte de Ana Cristina. A tese da Maria Lúcia de Barros comporta uma transcrição de um material que depois vai ser editado em livro, como os textos de Escritos da Inglaterra (1988) e Escritos no Rio (1993). Este trabalho acadêmico de excelência analisa a obra de Ana Cristina a partir dos textos, dos poemas e de todo o material reunido das pastas da escritora, como o ensaio "Pensamentos sublimes sobre o ato de traduzir" (Alguma Poesia Jornal, 1985, que é um texto fundamental para entender a Ana Cristina Cesar e que não estava publicado em livro até então.

A pesquisa que realizo se inscreve depois, no segundo momento, já com muito material à disposição. Além do trabalho interpretativo, busquei as fontes, o contexto e, por isso, usei o Escritos que já estavam disponíveis,

1 «De Bliss a Luvas de Pelica»: la métamorphose d'un conte. Publicado em Les Cahiers du CREPAL, n. 5. Paris: Presses de la Sorbonne Nouvelle, 1998, p. 79-97 e sob o título «Métamorphoses d'un conte de Bliss à Luvas de Pelica» na Revista da anpoll, v. 1, n. 5, 1988. Disponível em: https://revistadaanpoll.emnuvens.com.br/revista/article/view/309/322 
a Correspondência Incompleta (1999), a qual a Heloisa Buarque de Holanda me deu acesso até antes da publicação, e o que foi muito importante para a tese, no sentido de localização de uma série de alusões e referências no texto da Ana Cristina Cesar, que se apresenta de forma muito cifrada, muito enigmática. Acessar as fontes diversas, então, era um pouco para entender e não para explicar a obra, e perceber as múltiplas referências que estavam encaixadas no poema. Os pais de Ana Cristina Cesar, Waldo Cesar e Maria Luísa Cesar, vivos na época, generosamente me deram acesso à biblioteca da filha, possibilitando também explorar a marginália da escritora. O acervo atualmente está à disposição no Instituto Moreira Salles, mas na época em que realizei a tese, não existia, e eu trabalhava na casa dos pais, com todas as edições das obras disponíveis. O que ainda me surpreende é que pesquisadores ainda estão descobrindo coisas novas no acervo, como a contribuição jornalística que você explora e eu acessei em partes, graças às pastas do arquivo póstumo. Outros materiais disponíveis, que não existiam na época do trabalho da Maria Lúcia de Barros Camargo e já pude acessar, foi a biografia do Ítalo Moriconi, O sangue de uma poeta (1996), dados como os contidos nas cartas em partes publicadas pelo Caio Fernando Abreu no Estadão (1995), entre outras informações fragmentadas que vão completando o quadro para se entender a poesia de Ana Cristina.

A minha entrada na obra da escritora, que se assemelha também à de Maria Lúcia, por isso me identifico e menciono o trabalho pioneiro, é pela poesia, não por aspectos pessoais ou pela história. A minha preocupação era não ler a poesia a partir da morte da Ana Cristina: o grande viés de leitura que o suicídio introduziu obviamente leva a entender tudo já pensando neste fim trágico, então isso impede de ver, por exemplo, o humor do texto. Muito irônico e cáustico, ele joga, brinca. Não dá para confiar numa leitura defendendo que no começo dos anos 1970 Ana Cristina Cesar já está pensando em suicídio, pelo que ela registra nos textos. Aquele projeto de carta, Correspondência completa (1979), é uma maravilha de humor e brincadeira, com coisas sérias por trás. Embora seja uma obra curta, ela é de uma densidade e de uma riqueza que faz com que as leituras não se esgotem até hoje. Se a Ana Cristina está presente e a obra viva dentro de nós, é porque é uma obra de uma potência extraordinária.

Existem leituras ingênuas da obra de Ana Cristina que, em geral, se identificam com a primeira pessoa e se firmam na revelação de segredos femininos, sem pudor, uma coisa meio voyeur, ou romântica. Não se trata de condenar essas leituras, mas enquanto crítico, nosso papel é apontar para a obra que vai muito além disso, e que apresenta tantas camadas e referências enterradas nos textos, ambiguidades e ambivalências cultivadas. As leituras ingênuas nos fazem perceber apenas uma parte da obra.

Outro grupo de leitores desconfia da qualidade da obra da Ana Cristina, a coloca como imatura, talvez pela sua ligação com a geração de 
literatura marginal. Contudo, o movimento do grupo, olhando de perto, é um pouco mais complexo do que aparenta e vai muito além da antologia dos 26 Poetas Hoje (1976), organizada pela Heloísa Buarque. O movimento marginal no Rio de Janeiro promoveu publicações excelentes e coisas fracas. Mas de novo lendo na chave da espontaneidade desta vez com preconceito negativo, uma parte vê a obra de Cesar como algo sem grande interesse, baseada em uma devassa íntima, e que não é digna da grande literatura. $\mathrm{O}$ que revela uma grande ignorância. Um estudo acirrado da poesia produzida por Ana Cristina Cesar mostra o quanto ela é sutil: joga com o depoimento, uma certa devassidão, e a máscara. Uma coisa que você nota quando vai ler o que ela leu, é o quanto Ana Cristina estava atenta ao jogo de máscaras no texto. Em inédito de $A$ teus pés, "te livrando...", ela aproveita um trecho de um artigo do Octávio Paz a esse respeito. Demorei muito tempo para identificar a referência, mas sabia que tinha uma alusão, até acessar um ensaio relativamente curto a respeito de um outro poeta mexicano, José Gorostiza, que mostra seu lado valeriano, racional, antes de salientar o recurso à máscara, ironia: "De manera semejante a lo que, según Freud, ocurre con los sueños, en cada poema hay diversas capas de signos y sentidos, castillos de alusiones, forest of mirrors". ${ }^{2}$ Ela vai justamente aproveitar esse trecho, reorganizando-o:

castillo de alusiones

forest of mirrors

o que demonstra o impacto que o texto e essa reflexão do teórico teve para ela, assim como alguns textos do Roland Barthes e outros teóricos, que a marcam de maneira semelhante.

A figura intelectual da Ana Cristina Cesar está muito atenta e instigada à uma questão central da literatura que é a relação com a vida, e não ignora reflexões sobre o eu na posição do outro e do crítico. $\mathrm{O}$ interessante é que quando ela publica $A$ teus pés, o Ivan Junqueira, que não é um poeta da vanguarda, entende de modo muito inteligente o classicismo da obra, reconhecendo o grande talento da Ana Cristina. Às vezes acho que as pessoas não percebem o tesouro que é essa obra, ao mesmo tempo complexa e imediatamente acessível, que comunica imediatamente uma emoção. Por isso não dá para condenar as leituras ingênuas, já que o texto também apresenta esse nível de compreensão. Um sinal de qualidade de uma obra é essa multiplicidade de níveis de leituras e interpretações, prometida a revisões como a de Machado de Assis.

II - Ana Cristina Cesar foi uma escritora frequentemente acessada nos estudos acadêmicos pela produção poética (lírica) ou pelos exercícios de tradução, que inclui nomes da literatura como Katherine Mansfield,

2 PAZ, Octavio. Las Peras del Olmo. Barcelona: Seix Barral, mai. 1978, p. 89. 
Sylvia Plath, Charles Baudelaire, só para citar alguns. Existe aí uma Ana Cristina Cesar leitora que também vai se firmar dentro da imprensa brasileira comentando criticamente livros, ou peças de teatro/filmes. $\mathrm{Na}$ tese sobre Ana Cristina Cesar, ao apontar para outros movimentos fundadores da literatura brasileira que antecederam a geração de 1970 /"nebulosa marginal", como o modernismo de 1920, a dita "geração de 1945 ", o concretismo, o neoconcretismo e a tropicália, de que forma Cesar leitora influencia a escritora a partir do acesso à esta produção poética /literária que a antecedeu e passa a compor a gênese do seu labor?

M. R.: Sim, existem trabalhos que comparam a Ana Cristina e a Sylvia Plath. Sabemos que a escritora brasileira leu a Sylvia Plath, menciona na correspondência o impacto dado pela obra da Plath que é, de fato, uma grande escritora. Mas a aproximação passa por ambas serem mulheres e poetas suicidas. No entanto quando você lê a Sylvia Plath, não tem nada a ver com a estética da Ana Cristina. A americana tem seus brilhos, os momentos incandescentes, mas não o mesmo humor de Cesar. O humor que chega pela Plath é muito depressivo, considerando o contexto de uma mulher que vai passar tempos em hospícios; a Ana Cesar não vive internada, até as trajetórias biográficas são diferentes. Você reduz uma obra a dois traços biográficos e já resolveu? É um modo muito preguiçoso de ler. O Silviano Santiago diria que de "vara curta".

Sobre os recursos da tese, não se trata exclusivamente de um trabalho de crítica genética, precisava situar o momento da poesia marginal no geral, por ser uma tese defendida na França: parte da banca precisava da contextualização, um trabalho historiográfico a partir do modernismo. O que me interessava e me interessa, quando parece que estou fazendo historiografia, é entender e formular as questões as quais tal momento, tal sincronia, tenta responder. Eu acho que o modernismo dentro do contexto dos anos 1920 está formulando questões relevantes na arte e propondo várias soluções: aponta para a modernização, se atualiza em relação ao que é o cenário literário e artístico internacional, e promove uma série de questões próprias ao movimento, a partir das quais você pode ler a realidade naquele momento.

Mapeei o movimento de poesia marginal sintetizando a bibliografia disponível e informações que encontrei no acervo de Ana Cristina Cesar. Como os escritores costumavam trocar publicações, tive acesso a muita produção que não era fácil de encontrar por ser efêmera. Situar e explicar a poesia marginal pode servir também para um certo público brasileiro entender esse movimento, que tinha uma certa coerência, com todas as diferenças internas, mas que estava respondendo, depois do modernismo e da poesia engajada, a todas essas experiências precedentes. A situação política no Brasil era de uma esquerda derrotada, esmagada, e a opção luta 
armada completamente reprimida. Então, importante tratar na história o movimento como uma gênese coletiva, de um momento.

Outro ponto da tese está mais ligado a uma atitude de crítica genética do texto. Busquei as fontes, não só literárias, mas biográficas, os nomes, e até pensei na época que uma forma de editar a Ana Cristina seria justamente, considerando esse labirinto por trás da obra, uma edição hypertextual, onde o leitor possa clicar em uma palavra e ter uma nota, como uma forma de mostrar todas as interrelações do texto, não explicar ou elucidar, que se trata de fulano ou de beltrano, que tal nome remete à alguém conhecido, o que importa é entender que pode não importar e pensar na perspectiva da multiplicação dos sentidos.

Ao pesquisá-la, eu estava executando a obra, não no sentido de uma execução mortífera, mas como um músico executa uma partitura, porque a obra da Ana Cristina suscita isso. Como é enigmática, cifrada, ela joga. Na menção ao detetive, em Luvas de Pelica (1980), já estão no texto os pequenos mistérios, os conchavos de mulheres, as coisas encenadas que levam o leitor a querer saber. $O$ texto da Ana Cristina Cesar suscita um desejo de curiosidade, de se intrometer, e entrei nessa lógica para também mostrar que nada era espontâneo por ali. A grande arte de Ana Cesar era fingir que era espontâneo, e ela consegue fingir muito bem, quando não é.

Se você retoma as primeiras edições marginais de Cenas de abril, Correspondência completa ou de Luvas de pelica, por exemplo, e coteja com a versão final de $A$ teus pés, você vê o quanto ela mexe no texto, reescreve, risca, elimina poemas, pode perceber que não é nada assim de primeiro jato. Todo o trabalho requer um esforço crítico que envolve uma concepção da literatura, no caso perceber o texto sempre como um work in progress, e não como uma coisa fechada, definitiva, imóvel, estática. A poesia da Ana Cristina Cesar, por exemplo, deixa mais brechas do que um poema do João Cabral, ela funciona de modo diferente. $\mathrm{O}$ fato de incluir na leitura a marginália vai, simultaneamente, abrir e de certo modo diluir o texto impresso.

Outro ponto que entendi aos poucos na pesquisa sobre Ana Cristina Cesar foi o quanto ela mobiliza a sedução. Quando falamos de Ana Cesar, estamos diante de um texto que seduz, ele mesmo sendo resultado de várias seduções. Os livros, por exemplo, têm um impacto e um efeito na hora que ela lê, o que é poeticamente aproveitado. Existe uma eletricidade no texto que nasce de uma eletricidade de vivência, de leituras. Percebi que outro movimento importante na criação e nos questionamentos de Cesar era a questão da tradução. Tradução também envolve um impacto de leitura, a sedução, acrescentada a conversão em uma outra língua e a questão do decifrar-recifrar. As línguas mobilizam muito Ana Cristina Cesar, considerando também as duas vezes que ela morou na Inglaterra e o fato dela ter atuado como professora de inglês nos anos 1970. Na sua segunda passagem pela Inglaterra, no final de 1979, ela reorienta muito 
rapidamente seu objeto de estudos, se transferindo de um curso de sociologia da literatura, que acha muito chato, para procurar aquele professor meio antigo que dá aulas sobre o que é traduzir literatura. Os estudos vão suscitar parte dos trabalhos publicados no Escritos da Inglaterra. Há uma paixão na tradução feita por Ana Cristina Cesar que mobiliza afetos, assim como importantes questões teóricas, como o sujeito cambia a sua personalidade mudando de língua. O que move a criação, um questionamento central da arte, é algo refletido em textos brilhantes como Carta de Paris e Pensamentos sublimes. No último, por exemplo, ela combina uma escrita poética com a escrita ensaística.

III - Quando você esteve no acervo de Ana Cristina Cesar, ainda na década de 1990, conseguiu identificar com precisão o pouco explorado trabalho da escritora como colaboradora literária e cultural de diversos impressos brasileiros nas décadas de 1970 e 1980. Alguns destes textos foram publicados em Escritos no Rio (1996) e em Crítica e Tradução (1999), mas boa parte segue inédito ao público. Assim como a produção poética, a crítica jornalística desenvolvida pela escritora é caracterizada pela multiplicidade e, nesta marcação, quais são as formas, ao seu ver, de possíveis entradas analíticas e de perspectivas editoriais de difusão da escritora, considerando também as escolhas curatoriais desta obra até aqui? Podemos perceber aspectos de resistência política e social da linguagem em quais momentos do percurso da escritora brasileira? Seria possível estabelecermos novos parâmetros estéticos na obra dela depois da circulação pela Inglaterra e em outros países da Europa?

M. R.: Há um movimento fundamental para compreender a Ana Cristina Cesar no momento que ela está na Inglaterra, segundo semestre de 1979 e em 1980. Com o afastamento do Rio, da família, e o mergulho nos estudos, ela tem uma liberdade também de dirigir os seus próprios interesses, desenvolvendo experiências artísticas no início da abertura, da anistia no Brasil, um cenário de volta dos exilados, de criação do Partido dos Trabalhadores, uma perspectiva política completamente nova. No momento em que surge a poesia marginal existe uma chapa de concreto em cima do país e impasses de vários tipos. Então, a conjuntura do começo de 1980 encontra uma virada pessoal e uma virada coletiva, um duplo movimento, social e político, que abre novos espaços. A poesia marginal já não é marginal nos anos 1980, a editora Brasiliense começa a acolher e a recuperar, e peneirar um pouco desse marginalismo. A teus pés é um sinal disso, assim como os livros do Paulo Leminski. As poesias voltam aos circuitos tradicionais de distribuição, de circulação. E os jornais também se tornam mais disponíveis e com os textos mais maduros ficou mais fácil para alguns escritores uma inserção no meio comercial. 
A Ana Cristina Cesar não conhece o fim da ditadura militar, não vive as Diretas Já, ela para em 1983. Embora cresça em um ambiente politizado, sobretudo pelo pai que é muito engajado, existe também uma tendência familiar em valorizar a boa menina protestante, mas em um ambiente ao mesmo tempo progressista e relativamente repressor, a nível dos costumes, marcando nitidamente alguns poemas de Cenas de abril e outros poemas da parte inédita de $A$ teus pés. O lado político engajado, contra a ditadura, humanista, também forma a Ana Cristina: ela é uma cabeça política. Na verdade, Ana Cristina não produz teorias, mas reflexões. É um ser reflexivo, e isso aparece de modo mais evidente na contribuição jornalística. Também, por isso, eu estava comparando-a ao Machado de Assis, a nível de ceticismo, da ideia que não se pode iludir, não se pode acreditar piamente, ter uma compaixão cega por algo, etc., um exemplo disso está na Carta de Paris quando ela brinca com os eternos exilados. As dificuldades ela experimenta na Inglaterra e na França dos anos 1980; o retorno ao Brasil, o medo, aparecem. O exílio é uma situação extremamente inconfortável, mas em que alguns em parte acabaram encontrando acomodações. Ela mexe com uma temática central do Cisne de Charles Baudelaire, transpõe essa questão do exílio, considerado no poema do Baudelaire em planos múltiplos, para a situação do exílio e do retorno dos exilados. Quando você percebe isso, já sabe que está diante de uma inteligência excepcional.

Se a gente for buscar ou tentar uma leitura política do texto e da poesia de Ana Cristina Cesar, eu diria sim, é possível, não de modo explícito porque trata-se de uma artista que vive desconfiada e vive desconfiando de crenças, de catecismos. Definitivamente não é um Geraldo Vandré da poesia. Agora, acredito que a poesia dela é política porque alerta sobre leituras ingênuas, e não me refiro à literatura, mas a própria sociedade, repleta de leituras ingênuas de mundo. Ana Cristina é nutrida do espírito da contracultura, que é mais atento a questões da ordem dos costumes e pessoais, do que da questão do poder ou de como conquistar o poder, por exemplo.

Outro interesse que se firma em Ana Cristina Cesar é a entrada pelo feminino. Ela, inclusive, poderia ter sido uma feminista. O movimento feminista já existe no Brasil, no final dos anos 1970 e começo de 1980, ela está muito atenta, lê, se informa. E questões que remetem ao íntimo, como gênero e sexualidade. É possível que hoje já tenha se atenuado bastante, mas quando comecei a pesquisa, eu tive que me submeter ao exame da família. Eu tinha dois artigos escritos sobre sedução, a Maria Luísa, mãe da Ana Cristina, olhou, leu e viu que não se tratava de sexo, e deu a benção. Ítalo Moriconi conta a mesma coisa quando ele escreveu a biografia, aquela tentativa de controle. Viver a sexualidade foi um momento de forte trauma da Ana Cristina Cesar, mas as turmas dela ficaram divididas entre o lado correto da família, do Armando Freitas Filho, e as relações homossexuais. 
Quando o Caio Fernando publica três ou quatro cartas da Ana Cristina no Estadão, a família fica furiosa. Primeiro, por uma questão de direitos, e segundo pela provocação: ele sabia que ia morrer e já liberou, certamente porque revelava uma Ana Cristina que não correspondia àquele perfil que a família queria construir. Em outra carta que ele entregou para a Flora Sussekind, da casa Rui Barbosa, mas não facilmente consultável, a escritora falava justamente da paixão que ela viveu com a Kátia Muricy. O que era engraçado, em termos, é que depois da morte da Ana Cristina uma coisa que ela meio que organizou durante a vida foi que as pessoas passassem a desempenhar os papéis que ela tinha orquestrado. Pois ela mesma, se sabe, estava atravessada com esse assunto pessoal. A homossexualidade da Ana Cristina Cesar era um tabu na família, eu acho que o raciocínio da mãe era que esse grupo fazia muito mal para ela, que toda loucura e piração da jovem Ana tinha a ver com o grupo, e a história com a Kátia Muricy que não foi, digamos, soft.

Outra dimensão que aparece nas cartas que o Caio Fernando Abreu publica é o interesse pelo esoterismo. Nas provas finais de Correspondência Incompleta, que a Heloísa Buarque de Hollanda me passou antes da última revisão do Waldo Cesar, nota-se diferenças. Já havia acontecido muitos cortes nas correspondências, para proteger pessoas, mas o pai fez outros para não expor alguns interesses de Ana Cristina Cesar. Eu passei muito tempo cotejando linha por linha as provas que eu tinha e a edição publicada, então vi os cortes. Não tem muita importância saber do esoterismo da escritora, mas eu acho curiosa a preocupação. Me espanta o nível de controle da recepção, por algo até indiferente na leitura.

IV - Se considerarmos que é da natureza da própria linguagem literária /artística (Roland Barthes) a promoção de relativos revolucionamentos pela linguagem, podemos perceber na obra de Ana Cristina Cesar características que a alinham nesta perspectiva de atuação? Pensar o poder da linguagem no sistema literário, de alguma forma, fazia parte do projeto da crítica proposta por Cesar?

M. R.: Quem escreve literatura conscientemente tem uma consciência implícita ou explícita da opacidade da linguagem. Por exemplo, você sabe que a palavra cachorro não morde nem late. A tradução reforçou essa consciência, em Ana Cristina Cesar, de que a língua não apenas designa coisas do mundo, não só objetos, mas ideias, conceitos, ações. Organiza o mundo, a nossa relação ao mundo, uma mediação que interfere, e permite suscitar uma série de incidentes ou acidentes na intercompreensão. $\mathrm{O}$ jogo de palavras, a ambiguidade, são todas as artimanhas das pequenas ciladas de linguagem que podem ser percebidos na obra da Ana Cristina. Me interessei, em Ana Cristina Cesar, inicialmente pela questão da sedução, mas não somente. Eu comecei traduzindo-a, me 
desfazendo aos poucos de uma compreensão como mera intrusão íntima. É traduzindo Ana Cristina Cesar que eu me defrontei com a dificuldade de traduzir: em vários momentos você não sabe se o sujeito é feminino ou masculino, aí muda a leitura do poema. Algumas coisas o português permite, você pode omitir pronome e sujeito, o francês não. Precisava optar e explicitar. Havia uma série de marcas que o francês tornava obrigatória, de gênero, sobretudo, e que em português podia deixar-se, assim, flutuando. E depois jogo de palavras: "Caio chutando pedras", em Fogo do final, Caio pode ser verbo, eu caio desequilibrado, ou Caio Fernando Abreu, etc. No caso, o que que você faz em francês? Caio ou Je tombe? Coloca uma nota e acaba com a graça?

Coisas mais requintadas ainda como o KM de Luvas de Pelica que uns identificam logo com Katherine Mansfield. Mas KM é também Katia Muricy. A Ana Cristina Cesar constrói os textos para você achar que descobriu uma referência ou uma fonte, mas por trás há uma outra eventualmente, sempre de um modo abissal. Sabemos Ana Cesar fascinada pela autobiografia escrita pela Gertrude Stein, que é uma falsa autobiografia, e pelo $F$ for fake de Orson Welles, tudo que chama a atenção para uma ilusão. A vocação da tradução é elucidar, mas Ana Cristina Cesar entendeu que não apenas decifra, mas cifra de novo, e que desse mecanismo ela poderia tirar proveito. Ela recorre à tradução na contramão, não para tornar inteligível, mas tornar ilegível, como é o caso da menção à "galeria nacional" no Luvas de pelica, para falar da National Galery. A tradução opacifica ao invés de tornar transparente: genial. Tudo como consciência aguda do papel e do lugar da linguagem não só na literatura, mas na comunicação, apostando que na verdade a regra não é a gente se entender, mas a gente não se entender. E eu tendo a acreditar nisso.

V - Ainda hoje é urgente olhar para a obra de Cesar? Quais diálogos ela, de antemão, estabelece com o contemporâneo e / ou com o porvir?

M. R.: Um elemento para se pensar a literatura é a inscrição no tempo. Ao contrário do documento, uma obra literária já vem falando não só com os contemporâneos, mas para outras gerações. Ela tem dois corpos: um no contexto que ela é produzida e um outro que vai derivando. Essa é a história da Odisseia, de Shakespeare, de Machado de Assis. O Machado, por exemplo, já é considerado um grande autor quando escreve Memórias Póstumas de Brás Cubas, e o Capistrano de Abreu, colunista da época, não entende o livro e escreve uma longa resenha para dizer que não entende. Ele vai resumindo capítulo por capítulo porque não sabe o que fazer com um livro que incomoda, há muita reação na época contra o seu suposto amoralismo. Hoje ninguém questiona o valor do livro. Do mesmo modo Dom Casmurro, que antes suscitava uma leitura machista e patriarcal favorável ao Bentinho, foi lido aos poucos em favor da Capitu que se torna 
a heroína e a vítima. Hoje Bentinho é um idiota. A obra carrega um veneno, um veneno bom que vai fazendo efeito de modo lento. Um potencial de significações já plantado no primeiro momento e que, como uma árvore, tem flores desabrochando uma a uma, revela cores, perfumes etc. É difícil dizer o que o Machado vai ser daqui a 100 anos, ou o que a Ana Cristina vai ser, mas acho que ela vai continuar no palco e no cenário, porque é a experiência coletiva dos estudos.

Tenho várias pistas de pesquisas, já dei algumas e poderia dar outras: os estudos de gênero são pratos cheios para ler Ana Cristina Cesar, nem sei se é a melhor entrada, mas pode até ser interessante. Existem outros níveis de leitura, como os pequenos mistérios, coisas ainda não decifradas. Quando você começa a frequentar de modo mais íntimo a obra da Ana Cristina, percebe certos truques, e não é à toa que Luvas de pelica termina com uma sessão de prestidigitação. São truques que não esgotam, inclusive, as leituras fazem aparecer os pequenos fascínios, as novas percepções. Ana Cristina Cesar articula de modo muito diferente o plano do documento e o plano da ficção. Ela é uma ilusionista, não é realista. Atitude que é fruto do modernismo, que procede a uma série de rearranjos de hierarquias, de expressões etc., e da contracultura. Ela mistura Lou Reed, Machado de Assis e Baudelaire. Ana Cristina é uma clássica, tem descrições dela em Lady, ela tem essa postura um pouco acima. Tem um texto que eu acho fraco de um ensaísta que se promove porque ele cruzou com a poeta em uma noite que ela estava fazendo uma sopa Knorr, ou coisa do tipo. Mas o que é interessante nesse tipo de descrições é que Ana Cristina Cesar mantém uma distância, um dos componentes do seu classicismo.

\section{Referências Bibliográficas}

ABREU, Caio Fernando. "Por aquelas escadas subiu feito uma diva". $O$ Estado de S. Paulo, Cultura. p. q1-q2. 29 jul. 1995.

BAUDELAIRE, Charles. cuvres complètes. Paris: Gallimard. 1975.

CESAR, Ana Cristina. A teus pés. Col. Cantadas literárias São Paulo: Brasiliense, 1982.

CESAR, Ana Cristina. Cenas de abril. Rio de Janeiro: Companhia brasileira de artes gráficas, jun-jul. 1979.

CESAR, Ana Cristina. Correspondência completa. Rio de Janeiro: Companhia brasileira de artes gráficas, 1979.

CESAR, Ana Cristina. Correspondência incompleta. Org. de Armando Freitas Filho e Heloisa Buarque de Hollanda. Rio de Janeiro: Aeroplano, 1999.

CESAR, Ana Cristina. Escritos da Inglaterra. São Paulo: Brasiliense, 1988. CESAR, Ana Cristina. Escritos no Rio. Org. e pref. de Armando Freitas Filho. São Paulo: Brasiliense; Rio de Janeiro: UFRJ, 1993. 
CESAR, Ana Cristina. Gants de peau $\mathcal{E}$ autres poèmes. Trad. de Michel Riaudel. Paris: Chandeigne; Librarie Portugaise, 2005.

CESAR, Ana Cristina. Inéditos e dispersos, São Paulo: Brasiliense, 1985.

CESAR, Ana Cristina. Luvas de pelica, Inglaterra: Ruddpell Reprographies, 1980.

CESAR, Ana Cristina. "Pensamentos sublimes sobre o ato de traduzir". Alguma poesia jornal, abr-jun. 1985. Republicado em Escritos no Rio, op. cit., p. 149-59.

CAMARGO, Maria Lucia de Barros. Atrás dos olhos pardos: uma leitura da poesia de Ana Cristina Cesar. Chapecó: Argos, 2003.

HOLLANDA, Heloísa Buarque de (org.). 26 poetas hoje. Rio de Janeiro: Aeroplano, 1998 [1ª ed.: Rio de Janeiro: Labor, 1976].

JUNQUEIRA, Ivan. “Ana Cristina César: a vocação do abismo”. O Estado de São Paulo, Caderno 2 /Outras Palavras. São Paulo: 3 jan. 1984.

MORICONI, Italo. Ana Cristina Cesar: o sangue de uma poeta. Rio de Janeiro: Relume-Dumará, 1996.

RIAUDEL, Michel. Intertextualité et transferts (Brésil, Etats-Unis, Europe): réécritures de la modernité poétique dans l'œuvre d'Ana Cristina Cesar (Rio de Janeiro, 1952-1983). (Thèse Doctorat en Littératures Comparées). Paris: École Doctorale Lettres, Langues, Spectacles, Université Paris X Nanterre, 2007, p. 622.

SANTIAGO, Silviano. "Singular e Anônimo". In: O Eixo e a Roda. Belo Horizonte: 1986, p. 95-105. Disponível em:

http://www.periodicos.letras.ufmg.br/index.php/o_eixo_ea_roda/articl e/view/4209

Recebido em 22 de novembro de 2019

Aprovado em 25 de novembro de 2019

Raquel Machado Galvão é doutoranda do programa de pós-graduação em Teoria e História Literária da Universidade Estadual de Campinas, com o projeto A Crítica Jornalística de Ana Cristina Cesar, sob a orientação de Marcos Siscar, com bolsa FAPESP. Foi bolsista de pesquisa FAPESP /BEPE, de janeiro a julho de 2019, na Sorbonne Université, em Paris, sob supervisão do professor Michel Riaudel. Publicou "Notícia é Agora”, no livro Impressões Capixabas: 165 anos de Jornalismo no Espírito Santo (2005), organizado por José Antônio Martinuzzo. Publicou também na Profundanças: antologia literária e fotográfica (2014) e organizou, com colegas, "Econocriativa": mapeamento e diagnóstico das editoras baianas (2016). Contato: raquelgcultura@gmail.com 